\section{Atendimentos por acidentes e violências na infância em serviços de emergências públicas}

\author{
Treatment of childhood injuries and violence in \\ public emergency services
}

\author{
Atención por accidentes y violencia contra la \\ infancia en servicios públicos de urgencias
}

\begin{abstract}
This study aimed to analyze the profile of treatment for accidents and violence involving children under 10 years of age in Brazil in the year 2011. This was a cross-sectional descriptive study in 71 emergency services in the Brazilian Unified National Health System (SUS), located in the national capital and 24 state capitals. Data were obtained from the Ministry of Health's system of sentinel surveillance services for Violence and Accidents (VIVA Survey). The highest proportion of injuries (67.4\%) occurred inside the child's home. Among unintentional injuries, falls were the most frequent (52.4\%), followed by running into objects or persons (21.8\%) and traffic injuries (10.9\%), especially as passengers (bicycles were an important means of transportation involved in the injuries). The vast majority of unintentional injuries are avoidable, and educational measures should be adopted, especially with parents, teachers, the community, and health workers, calling attention to the risks and the adoption of safe behaviors in the home, at school, and in leisure-time activities. Cases of violence are subject to mandatory reporting, and prompt measures should be taken to protect victims.
\end{abstract}

Child; Wounds and Injuries; Violence; External Causes; Emergency Medical Services
Deborah Carvalho Malta 1,2

Márcio Denis Medeiros Mascarenhas 2,3 Alice Cristina Medeiros das Neves 2 Marta Alves da Silva ${ }^{2}$

\section{Resumo}

O objetivo deste artigo foi analisar o perfil dos atendimentos de emergência por acidentes e violências envolvendo crianças menores de 10 anos no Brasil no ano de 2011. Foi realizado estudo transversal, descritivo, em 71 serviços de urgência e emergência no âmbito do SUS, localizados no Distrito Federal e em 24 capitais brasileiras. Os dados foram obtidos no sistema de serviços sentinelas de Vigilância de Violências e Acidentes (VIVA Inquérito), do Ministério da Saúde. A maior proporção das lesões $(67,4 \%)$ ocorreu no ambiente domiciliar. Dentre as injúrias não intencionais, as quedas foram a ocorrência mais frequente (52,4\%), seguidas de choque contra objetos/pessoas (21,8\%) e lesões no trânsito (10,9\%), destacando-se as vítimas na condição de passageiros, e dentre os meios de locomoção da vítima são destaque as bicicletas. As injúrias não intencionais na grande maioria são evitáveis e devem ser adotadas medidas educativas, em especial junto aos pais, educadores, comunidade, profissionais de saúde e educação, alertando para os riscos e adoção de comportamentos seguros em relação ao ambiente doméstico, escola e de lazer. As violências são objeto de notificação obrigatória, e as ações de proteção às vítimas devem ser instituídas prontamente.

Criança; Ferimentos e Lesões; Violência; Causas Externas; Serviços Médicos de Emergência 


\section{Introdução}

As causas externas (acidentes e violências) constituem a principal causa de morte entre crianças a partir de 1 ano de idade e adolescentes, tornando-se um relevante problema de saúde pública para famílias e sociedade 1,2. Esses agravos também são responsáveis por eventos não fatais e sequelas que podem afetar, negativamente, a qualidade de vida de crianças e adolescentes 1,3.

Segundo a Organização Mundial da Saúde (OMS) 1, a cada ano, cerca de 830 mil crianças morrem vítimas de causas externas, cuja magnitude atinge principalmente países da África e Ásia. Em 2010, ocorreram 3.815 óbitos de crianças de 0-9 anos por causas externas no Brasil (7,5\% dos óbitos nesta faixa), ficando atrás apenas das mortes decorrentes de causas perinatais e malformações. Cerca de um terço desses óbitos refere-se aos acidentes de transporte, afogamentos, asfixias, agressões e quedas 2 (Departamento de Informática do SUS. Informações de saúde. http://www.datasus.gov.br, acessado em 15/ Mar/2013).

Destacam-se ainda as ocorrências de violência na infância pela vulnerabilidade das vítimas, incapazes de se defender, e pelos danos emocionais e físicos a elas causados. A violência familiar é o tipo mais frequente nessa faixa etária e é perpetrada por membros da própria família 4,5 . Além da agressão, expressão mais conhecida, a violência doméstica se manifesta sob outras formas como a negligência ou qualquer outro tipo de omissão que prejudique o bem-estar, a integridade física, psicológica, a liberdade e o desenvolvimento humano 5,6.

O Ministério da Saúde implantou em 2006 o sistema de Vigilância de Violências e Acidentes (VIVA Inquérito), que se caracteriza por inquérito bianual nos serviços de urgência e emergência da rede assistencial do Sistema Único de Saúde (SUS). Por meio desse inquérito, torna-se possível monitorar os atendimentos relacionados às causas externas (acidentes e violências), tanto os graves quanto aqueles de menor gravidade. O VIVA Inquérito constitui uma estratégia de vigilância e monitoramento da distribuição, magnitude e tendência desses agravos e de seus fatores de risco, visando a subsidiar o planejamento e a aplicação de intervenções apropriadas de prevenção e promoção à saúde nos diferentes segmentos populacionais como, por exemplo, a população infantil ${ }^{3}$.

O presente trabalho tem como objetivo analisar o perfil dos atendimentos por acidentes e violências envolvendo crianças menores de 10 anos em serviços públicos de urgência e emergência no Brasil.

\section{Métodos}

Trata-se de um estudo transversal, descritivo, realizado em 71 serviços de urgência e emergência no âmbito do SUS, localizados no Distrito Federal e em 24 capitais brasileiras, no ano de 2011. Manaus, Amazonas e São Paulo não executaram o inquérito por aspectos operacionais.

Para selecionar os serviços de saúde incluídos no trabalho, realizou-se consulta ao Cadastro Nacional de Estabelecimentos de Saúde (CNES) para identificar os serviços de referência para o atendimento de emergência às vítimas de causas externas, os quais foram analisados quanto à demanda de atendimento por causas externas informada no Sistema de Informações Hospitalares do SUS (SIH/SUS) e VIVA Inquérito (para os serviços participantes da pesquisa nos anos de 2006, 2007 e 2009). A inclusão dos serviços selecionados foi validada pelos coordenadores da Vigilância de Doenças e Agravos Não Transmissíveis (VDANT) das secretarias de saúde dos estados e municípios participantes da pesquisa.

A população do estudo foi composta por todas as vítimas de acidentes e violências que procuraram atendimento nos serviços de urgência e emergência selecionados, e que concordaram em participar da pesquisa, excetuando-se as vítimas que procuraram atendimentos por esta ocorrência pela segunda ou mais vezes, a exemplo de retornos médicos e/ou complicações da assistência. Considerando-se o critério de precisão para as estimativas de prevalências fixadas para o estudo, o tamanho da amostra foi de, no mínimo, 2 mil atendimentos por causas externas em cada uma das capitais e no Distrito Federal, assumindo coeficiente de variação inferior a $30 \%$ e o erro-padrão menor que 3 . Foram sorteados turnos de atendimentos nos serviços de urgência pesquisados.

Considerou-se o período de coleta de 30 dias, entre os meses de setembro e outubro de 2011, dividido em turnos de 12 horas, totalizando 60 turnos. O número de turnos sorteados em cada estabelecimento foi obtido pela razão entre o tamanho mínimo da amostra de atendimentos por causas externas ( 2 mil) e a média de atendimentos por causas externas realizados no mesmo estabelecimento em anos anteriores à pesquisa. $\mathrm{O}$ procedimento de sorteio dos turnos foi a amostragem por conglomerado em único estágio estratificado pelo estabelecimento, sendo o turno a unidade primária de amostragem. Todos os atendimentos por causas externas do turno sorteado foram incluídos na amostra ${ }^{3}$. Mais informações sobre o delineamento da amostra podem ser obtidas em publicação específica ${ }^{3}$. Foram analisa- 
das todas as ocorrências em menores de 10 anos de idade $(n=7.224)$.

Os dados foram coletados usando-se formulário padronizado. Os atendimentos foram classificados em dois grupos (violências e acidentes) por meio das respostas obtidas durante as entrevistas e segundo as definiçõos constantes da 10a revisão da Classificação Estatística Internacional de Doenças (CID-10), referentes ao capítulo XX - causas externas de morbidade e mortalidade.

Para o presente trabalho, foram considerados atributos individuais, desfecho da ocorrência e características do acidente e da violência. Foram analisadas as seguintes variáveis: sexo, faixa etária (0-1 ano, 2-5 anos, 6-9 anos), raça/cor da pele, meios de locomoção utilizados para chegar ao serviço de urgência, local de ocorrência, natureza da lesão, parte do corpo atingida, turno e dia de atendimento, evolução na emergência, tipo de evento e tipo de vítima.

As análises foram feitas para o conjunto de crianças menores de 10 anos de idade, atendidas nos serviços sentinela das 24 capitais e no Distrito Federal, comparando-se as características das vítimas de acidentes e de violência, estratificadas por faixa etária. A hipótese nula de independência entre as variáveis qualitativas foi averiguada pelo teste do qui-quadrado com nível de significância de 5\%. Utilizou-se o módulo svy do programa Stata, versão 11 (Stata Corp., College Station, Estados Unidos), para a obtenção de estimativas não viciadas quando os dados são provenientes de planos de amostragem complexos.

O projeto do VIVA Inquérito 2011 foi avaliado e aprovado pela Comissão Nacional de Ética em Pesquisa (CONEP), do Ministério da Saúde. A coleta de dados foi realizada após a concordância das vítimas ou de seus responsáveis ou acompanhantes, quando menores de 18 anos, ou quando se tratava de vítima inconsciente.

\section{Resultados}

Foram registrados 7.224 atendimentos de emergência por acidentes e violências entre crianças de 0-9 anos de idade, sendo 7.043 (97,5\%) vítimas de acidentes e 181 (2,5\%), de violências. Do total de crianças, $19,5 \%$ tinham até 1 ano de idade, $42,7 \%$ de $2-5$ anos e $37,7 \%$ de $6-9$ anos; destaca-se a ocorrência de acidentes em crianças de $2-5$ anos e de violências em crianças de 6-9 anos (valor de $\mathrm{p}<0,001$ ). Quanto à raça/cor da pele, $62,2 \%$ eram negros (pretos/pardos), 35,6\% brancos; a maioria das ocorrências aconteceu no domicílio $(67,4 \%)$, sendo este local associado estatisticamente aos acidentes (valor de $\mathrm{p}<0,001$ ); as contusões foram as lesões mais frequentes (31,5\%), seguidas dos cortes (30,5\%). A cabeça e pescoço $(42,8 \%)$ foram os segmentos corporais mais atingidos, em especial nos casos de violência (valor de $\mathrm{p}<0,001$ ). A locomoção para o hospital foi mais frequente em veículo particular (56,6\%). Os atendimentos predominaram no período diurno e durante a semana, sem diferença estatística entre os tipos de ocorrência. A maioria dos atendimentos teve a alta como desfecho $(81,6 \%)$ (Tabela 1$)$.

$\mathrm{Na}$ análise por faixa etária, os meninos foram os mais acidentados em todas elas, predominando a faixa etária de $6-9$ anos $(64,2 \%$; valor de $\mathrm{p}<0,001)$. Nos casos de violência, os meninos também predominaram, com exceção da faixa de 2-5 anos de idade, na qual as meninas foram as vítimas mais frequentes $(59,3 \%$; valor de $\mathrm{p}<0,001)$. A raça/cor predominante em acidentes foi a negra (preta/parda), com destaque para os participantes de 6-9 anos (67,4\%; valor de $\mathrm{p}<0,001$ ), e sem diferença estatística segundo faixa etária para os atendimentos por violências. As ocorrências foram mais frequentes no domicílio, principalmente entre as crianças de 0 - 1 ano, tanto nos acidentes $(88,9 \%)$ como nas violências (75,5\%; valor de $\mathrm{p}<0,001)$. Dentre os acidentes, as contusões foram as lesões mais frequentes em 0-1 ano, os cortes predominaram em 2-5 anos, e as fraturas em crianças de 6-9 anos (valor de $\mathrm{p}<0,001)$. Os cortes foram as lesões mais frequentes nos atendimentos por violência. Nos episódios de acidentes, a cabeça foi a região mais atingida em $0-1$ ano $(55,5 \%)$ e os membros superiores em crianças de 6-9 anos (valor de $\mathrm{p}<0,001$ ); dentre os atendimentos por violência, predominaram as ocorrências na cabeça, sem diferença segundo faixa etária. Não houve associação entre meio de locomoção para o hospital e faixa etária das vítimas de acidentes ou violências. Os eventos foram mais frequentes durante o dia e em dias de semana, e a alta foi o desfecho mais frequente na evolução na emergência durante as primeiras 24 horas, sem identificação de diferenças significativas segundo faixa etária (Tabela 2).

Como pode ser observado na Tabela 3, as quedas $(52,4 \%)$ e outros acidentes $(33,6 \%)$ foram as ocorrências que levaram à maior proporção de atendimentos nos serviços de urgência e emergência, seguidos dos acidentes de transporte (10,9\%) e queimaduras (3\%). A ocorrência mais frequente em crianças de até 1 ano de idade foi a queda $(60,9 \%$; valor de $\mathrm{p}<0,001)$, predominando as quedas do leito/mobília (43,7\%; valor de $\mathrm{p}<0,001)$. Dentre as crianças de 2-9 anos, as quedas do mesmo nível foram mais frequentes. $\mathrm{O}$ segundo evento mais frequente foram os outros acidentes, destacando-se: entorse/esmagamento $(23,2 \%)$ no grupo de $0-1$ ano, e choque contra 
Tabela 1

Atendimentos de emergência por acidentes e violência entre crianças segundo tipo de ocorrência, 24 capitais e Distrito Federal, Brasil, setembro a outubro, 2011.

\begin{tabular}{|c|c|c|c|c|}
\hline \multirow[t]{3}{*}{ Características } & \multicolumn{3}{|c|}{ Tipo de ocorrência (\%) * } & \multirow[t]{3}{*}{ Valor de $p$ ** } \\
\hline & Acidentes & Violência & Total & \\
\hline & $(n=7.043)$ & $(n=181)$ & $(n=7.224)$ & \\
\hline Faixa etária (anos) & & & & 0,000 \\
\hline $0-1$ & 19,7 & 14,6 & 19,5 & \\
\hline $2-5$ & 43,3 & 21,7 & 42,7 & \\
\hline $6-9$ & 37,0 & 63,8 & 37,7 & \\
\hline Sexo & & & & 0,941 \\
\hline Masculino & 60,5 & 60,2 & 60,5 & \\
\hline Feminino & 39,5 & 39,9 & 39,5 & \\
\hline Raça/Cor & & & & 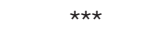 \\
\hline Branca & 35,8 & 31,3 & 35,6 & \\
\hline Preta/Parda & 62,1 & 67,8 & 62,2 & \\
\hline Amarela/Indígena & 2,2 & 0,9 & 2,2 & \\
\hline Local de ocorrência & & & & 0,000 \\
\hline Domicílio \# & 67,9 & 47,4 & 67,4 & \\
\hline Fora do domicílio \#\# & 32,1 & 52,6 & 32,6 & \\
\hline Natureza da lesão & & & & 0,125 \\
\hline Sem lesão & 10,8 & 8,2 & 10,8 & \\
\hline Contusão/Entorse/Luxação & 31,7 & 24,6 & 31,5 & \\
\hline Corte/Laceração & 30,3 & 40,7 & 30,5 & \\
\hline Fratura/Amputação/Traumas \#\#\# & 19,1 & 18,0 & 19,1 & \\
\hline Outros $\S$ & 8,1 & 8,4 & 8,1 & \\
\hline Parte do corpo atingida & & & & 0,000 \\
\hline Cabeça/Pescoço & 42,6 & 50,2 & 42,8 & \\
\hline Tórax/Abdome/Pélvis & 4,5 & 8,7 & 4,6 & \\
\hline Membros superiores & 27,9 & 25,2 & 27,8 & \\
\hline Membros inferiores & 19,8 & 7,1 & 19,4 & \\
\hline Múltiplos órgãos/regiões & 5,2 & 8,9 & 5,3 & \\
\hline Locomoção para o hospital & & & & 0,068 \\
\hline A pé/Coletivo (ônibus/micro-ônibus) & 23,8 & 28,3 & 24,0 & \\
\hline Veículo particular & 56,8 & 47,6 & 56,6 & \\
\hline SAMU/Ambulância/Resgate & 17,4 & 19,2 & 17,4 & \\
\hline Outros $\S$ & 2,0 & 4,9 & 2,1 & \\
\hline Período de atendimento & & & & 0,492 \\
\hline Diurno & 66,8 & 70,2 & 66,9 & \\
\hline Noturno & 33,2 & 29,9 & 33,1 & \\
\hline Dia de atendimento & & & & 0,326 \\
\hline Sábado e domingo & 29,4 & 23,0 & 29,2 & \\
\hline Segunda a sexta & 70,6 & 77,0 & 70,8 & \\
\hline Evolução na emergência (primeiras 24 horas) & & & & *** \\
\hline Alta & 81,7 & 78,8 & 81,6 & \\
\hline Internação hospitalar §§§ & 11,6 & 14,0 & 11,7 & \\
\hline Encaminhamento ambulatorial & 5,9 & 7,3 & 5,9 & \\
\hline Outros ${ }^{\dagger}$ & 0,8 & 0,0 & 0,8 & \\
\hline
\end{tabular}

SAMU: Serviço de Atendimento Móvel de Emergência.

* Para algumas variáveis o número de atendimentos divergiu devido a dados faltantes (ignorado/em branco);

** Teste do qui-quadrado;

*** Não foram calculados o teste do qui-quadrado e o valor de p devido à existência de célula com valor $<5$;

\# Inclui residência e habitação coletiva;

\#\# Inclui bar ou similar, comércio/serviços, indústrias/construção e outros;

\#\#\# Inclui trauma cranioencefálico, trauma dentário e politraumatismo;

$\S$ Inclui intoxicação, queimadura e outros;

$\S \S$ Inclui viatura policial e outros;

$\S \S \S$ Inclui internação hospitalar e encaminhamento para outro serviço;

† Inclui evasão/fuga, óbito e outros.

Fonte: Secretaria de Vigilância em Saúde, Ministério da Saúde. Sistema de Vigilância de Violências e Acidentes - VIVA Inquérito 2011. 
Atendimentos de emergência por acidentes entre crianças segundo faixa etária, 24 capitais e Distrito Federal, Brasil, setembro a outubro, 2011.

\begin{tabular}{|c|c|c|c|c|c|c|c|c|c|c|}
\hline \multirow[t]{2}{*}{ Características } & \multicolumn{4}{|c|}{$\begin{array}{c}\text { Acidentes (\%) } \\
\text { Faixa etária (anos) * }\end{array}$} & \multirow[t]{2}{*}{$\begin{array}{l}\text { Valor } \\
\text { de } p^{* *}\end{array}$} & \multicolumn{4}{|c|}{$\begin{array}{c}\text { Violências (\%) } \\
\text { Faixa etária (anos) * }\end{array}$} & \multirow[t]{2}{*}{$\begin{array}{l}\text { Valor } \\
\text { de } p^{* *}\end{array}$} \\
\hline & $\begin{array}{c}0-1 \\
(n=1.391)\end{array}$ & $\begin{array}{c}2-5 \\
(n=3.048)\end{array}$ & $\begin{array}{c}6-9 \\
(n=2.604)\end{array}$ & $\begin{array}{c}\text { Total } \\
(\mathrm{n}=7.043)\end{array}$ & & $\begin{array}{c}0-1 \\
(n=35)\end{array}$ & $\begin{array}{c}2-5 \\
(n=46)\end{array}$ & $\begin{array}{c}6-9 \\
(n=100)\end{array}$ & $\begin{array}{c}\text { Total } \\
(n=181)\end{array}$ & \\
\hline Sexo & & & & & 0,000 & & & & & 0,011 \\
\hline Masculino & 54,7 & 59,9 & 64,2 & 60,5 & & 54,2 & 40,7 & 68,1 & 60,2 & \\
\hline Feminino & 45,3 & 40,1 & 35,8 & 39,5 & & 45,9 & 59,3 & 31,9 & 39,9 & \\
\hline Raça/cor & & & & & 0,000 & & & & & 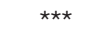 \\
\hline Branca & 44,0 & 36,6 & 30,4 & 35,8 & & 53,1 & 27,0 & 27,8 & 31,3 & \\
\hline Preta/Parda & 54,0 & 61,2 & 67,4 & 62,1 & & 43,8 & 71,9 & 71,9 & 67,8 & \\
\hline Amarela/Indígena & 2,0 & 2,2 & 2,2 & 2,2 & & 3,1 & 1,1 & 0,3 & 0,9 & \\
\hline Local de ocorrência & & & & & 0,000 & & & & & 0,000 \\
\hline Domicílio \# & 88,9 & 73,7 & 50,1 & 67,9 & & 76,5 & 64,8 & 35,0 & 47,4 & \\
\hline Fora do domicílio \#\# & 11,2 & 26,3 & 49,9 & 32,1 & & 23,5 & 35,2 & 65,0 & 52,6 & \\
\hline Natureza da lesão & & & & & 0,000 & & & & & 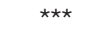 \\
\hline Sem lesão & 14,0 & 13,0 & 6,7 & 10,8 & & 5,4 & 11,1 & 7,8 & 8,2 & \\
\hline Contusão/Entorse/Luxação & 36,2 & 27,0 & 34,8 & 31,7 & & 38,9 & 18,3 & 23,7 & 24,6 & \\
\hline Corte/Laceração & 20,2 & 34,2 & 31,0 & 30,3 & & 23,8 & 46,5 & 42,4 & 40,7 & \\
\hline Fratura/Amputação/Traumas \#\#\# & 16,7 & 17,3 & 22,5 & 19,1 & & 8,2 & 8,9 & 23,2 & 18,0 & \\
\hline Outros § & 12,9 & 8,6 & 5,1 & 8,1 & & 23,7 & 15,2 & 2,8 & 8,4 & \\
\hline Parte do corpo atingida & & & & & 0,000 & & & & & $\star \star \star \star ~$ \\
\hline Cabeça/Pescoço & 55,5 & 48,7 & 29,6 & 42,6 & & 28,6 & 58,5 & 52,5 & 50,2 & \\
\hline Tórax/Abdome/Pélvis & 4,1 & 4,6 & 4,6 & 4,5 & & 10,5 & 5,3 & 9,4 & 8,7 & \\
\hline Membros superiores & 22,6 & 24,1 & 34,5 & 27,9 & & 36,3 & 19,2 & 24,6 & 25,2 & \\
\hline Membros inferiores & 10,5 & 17,2 & 27,1 & 19,8 & & 1,5 & 11,9 & 6,8 & 7,1 & \\
\hline Múltiplos órgãos/regiões & 7,3 & 5,4 & 4,1 & 5,2 & & 23,1 & 5,1 & 6,8 & 8,9 & \\
\hline Locomoção para o hospital & & & & & 0,098 & & & & & 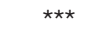 \\
\hline $\begin{array}{l}\text { A pé/Coletivo (ônibus/micro- } \\
\text { ônibus) }\end{array}$ & 21,1 & 24,6 & 24,4 & 23,8 & & 15,1 & 10,8 & 37,1 & 28,3 & \\
\hline Veículo particular & 59,0 & 57,2 & 55,2 & 56,8 & & 46,8 & 67,7 & 41,1 & 47,6 & \\
\hline SAMU/Ambulância/Resgate & 16,9 & 16,7 & 18,3 & 17,4 & & 38,1 & 19,1 & 15,0 & 19,2 & \\
\hline Outros $\S \S$ & 3,0 & 1,5 & 2,1 & 2,0 & & 0,0 & 2,4 & 6,8 & 4,9 & \\
\hline Período de atendimento & & & & & 0,001 & & & & & 0,177 \\
\hline Diurno & 63,2 & 65,5 & 70,2 & 66,8 & & 52,9 & 70,3 & 74,1 & 70,2 & \\
\hline Noturno & 36,8 & 34,5 & 29,8 & 33,2 & & 47,2 & 29,8 & 25,9 & 29,9 & \\
\hline Dia de atendimento & & & & & 0,142 & & & & & 0,036 \\
\hline Sábado e domingo & 28,5 & 31,1 & 28,0 & 29,4 & & 44,6 & 23,6 & 17,9 & 23,0 & \\
\hline Segunda a sexta & 71,5 & 69,0 & 72,0 & 70,6 & & 55,4 & 76,4 & 82,1 & 77,0 & \\
\hline Evolução na emergência & & & & & 0,127 & & & & & 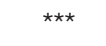 \\
\hline (primeiras 24 horas) & & & & & & & & & & \\
\hline Alta & 81,3 & 82,6 & 80,8 & 81,7 & & 77,3 & 66,2 & 83,5 & 78,8 & \\
\hline Internação hospitalar §§§ & 13,1 & 11,1 & 11,4 & 11,6 & & 22,7 & 19,5 & 10,1 & 14,0 & \\
\hline Encaminhamento ambulatorial & 5,0 & 5,6 & 6,7 & 5,9 & & 0,0 & 14,3 & 6,4 & 7,3 & \\
\hline Outros ${ }^{\dagger}$ & 0,6 & 0,7 & 1,1 & 0,8 & & & & & & \\
\hline
\end{tabular}

SAMU: Serviço de Atendimento Móvel de Urgência.

* Para algumas variáveis o número de atendimentos divergiu devido a dados faltantes (ignorado/em branco);

** Teste do qui-quadrado:

*** Não foram calculados o teste do qui-quadrado e o valor de $p$ devido à existência de célula com valor $<5$;

\# Inclui residência e habitação coletiva;

\#\# Inclui bar ou similar, comércio/serviços, indústrias/construção e outros;

\#\#\# Inclui trauma cranioencefálico, trauma dentário e politraumatismo;

$\S$ Inclui intoxicação, queimadura e outros;

$\S \S$ Inclui viatura policial e outros;

$\S \S \S$ Inclui internação hospitalar e encaminhamento para outro serviço;

† Inclui evasão/fuga, óbito e outros.

Fonte: Secretaria de Vigilância em Saúde, Ministério da Saúde. Sistema de Vigilância de Violências e Acidentes - VIVA Inquérito 2011. 
Atendimentos de emergência por acidentes entre crianças segundo características dos eventos por faixa etária, 24 capitais e Distrito Federal, Brasil, setembro a outubro, 2011.

\begin{tabular}{|c|c|c|c|c|c|}
\hline \multirow[t]{2}{*}{ Características } & \multicolumn{4}{|c|}{ Faixa etária (\%) [anos] * } & \multirow[t]{2}{*}{ Valor de $p^{* \star}$} \\
\hline & $0-1$ & $2-5$ & $6-9$ & Total & \\
\hline Tipo de acidente (n) & $(1.391)$ & $(3.048)$ & $(2.604)$ & $(7.043)$ & 0,000 \\
\hline Acidente de transporte & 4,8 & 10,1 & 15,1 & 10,9 & \\
\hline Queda & 60,9 & 51,8 & 48,6 & 52,4 & \\
\hline Queimadura & 7,6 & 2,3 & 1,5 & 3,0 & \\
\hline Outros acidentes & 26,7 & 35,8 & 34,8 & 33,6 & \\
\hline Acidente de transporte: tipo de vítima ( $n$ ) & (76) & $(342)$ & $(386)$ & $(804)$ & 0,000 \\
\hline Pedestre & 13,4 & 22,4 & 30,3 & 25,7 & \\
\hline Condutor & 22,0 & 24,6 & 42,8 & 33,7 & \\
\hline Passageiro & 64,7 & 52,9 & 26,9 & 40,6 & \\
\hline Acidente de transporte: meio de locomoção da vítima (n) & $(77)$ & $(342)$ & $(387)$ & $(806)$ & 0,000 \\
\hline A pé & 9,8 & 21,8 & 29,8 & 24,9 & \\
\hline Automóvel & 24,9 & 9,1 & 5,9 & 8,8 & \\
\hline Motocicleta & 12,7 & 11,8 & 5,8 & 8,8 & \\
\hline Bicicleta & 26,8 & 51,8 & 51,4 & 49,4 & \\
\hline Ônibus/Micro-ônibus/Outros & 25,8 & 5,4 & 7,3 & 8,2 & \\
\hline Tipo de queda (n) & $(835)$ & $(1.573)$ & $(1.218)$ & $(3.626)$ & 0,000 \\
\hline Mesmo nível & 33,5 & 47,5 & 58,8 & 48,2 & \\
\hline Leito/Mobília & 43,7 & 25,0 & 9,0 & 23,8 & \\
\hline Escada/Degrau & 10,6 & 12,8 & 8,8 & 11,0 & \\
\hline Árvore/Telhado/Andaime/Laje & 0,4 & 1,8 & 7,7 & 3,5 & \\
\hline Buraco/Outros níveis & 11,8 & 12,8 & 15,6 & 13,6 & \\
\hline Tipo de queimadura (n) & (99) & (64) & $(40)$ & $(203)$ & 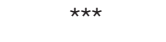 \\
\hline Fogo/Chama & 9,3 & 16,4 & 26,8 & 14,8 & \\
\hline Substância quente & 59,0 & 43,2 & 48,3 & 51,9 & \\
\hline Objeto quente & 27,4 & 23,1 & 14,4 & 23,6 & \\
\hline Outros \# & 4,3 & 17,3 & 10,6 & 9,7 & \\
\hline Outros acidentes $(n)$ & $(370)$ & $(1.049)$ & (943) & $(2.362)$ & 0,000 \\
\hline Ferimento cortante & 5,2 & 10,3 & 15,2 & 11,4 & \\
\hline Acidentes com animais & 11,1 & 12,4 & 12,9 & 12,4 & \\
\hline Queda de objeto sobre a pessoa & 13,3 & 8,8 & 7,8 & 9,1 & \\
\hline Choque contra objeto/Pessoa & 13,8 & 16,6 & 31,2 & 21,8 & \\
\hline Entorse/Esmagamento & 23,2 & 10,9 & 13,6 & 13,8 & \\
\hline Outros \#\# & 33,3 & 41,1 & 19,3 & 31,5 & \\
\hline
\end{tabular}

* Para algumas variáveis o número de atendimentos divergiu devido a dados faltantes (ignorado/em branco);

** Teste do qui-quadrado;

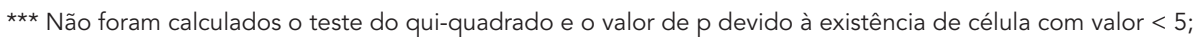

\# Inclui objeto quente, choque elétrico e substâncias químicas.

\#\# Inclui sufocação/engasgamento, corpo estranho, afogamento, envenenamento/intoxicação, ferimento por arma de fogo, outros.

Fonte: Secretaria de Vigilância em Saúde, Ministério da Saúde. Sistema de Vigilância de Violências e Acidentes VIVA Inquérito 2011.

objeto/pessoa em crianças de 2-5 anos e de 6-9 anos (16,6\% e 31,2\% respectivamente; valor de $\mathrm{p}$ $<0,001)$. Os acidentes de transportes predominaram em crianças de 6-9 anos (15,1\%). As vítimas na condição de passageiros foram as mais comuns $(40,6 \%)$, especialmente entre as crianças de 0 - 1 ano $(64,7 \%)$; os acidentes com pedestres/ atropelamentos predominaram no grupo de 6-9 
anos (30,3\%), assim como as vítimas na condição de condutores $(42,8 \%$; valor de $\mathrm{p}<0,001)$. A bicicleta (velocípedes, triciclos não motorizados e similares) $(49,4 \%)$ foi o meio de locomoção da vítima mais frequente, em especial entre as crianças de $2-5$ anos $(51,8 \%)$. As queimaduras (3\%) foram mais frequentes no grupo de $0-1$ ano $(7,6 \%)$, sendo as causadas por substâncias quentes as predominantes em todas as faixas de idade $(51,9 \%)$.

A agressão física foi mais frequente em crianças de 6-9 anos (95,8\%; valor de $\mathrm{p}<0,001)$, e a negligência predominou entre as crianças mais jovens $(32,4 \%$; valor de $\mathrm{p}<0,001)$. A violência sexual ocorreu em $2,5 \%$ das vítimas de violência, predominando entre as crianças de $2-5$ anos $(4,6 \%)$. O agressor era um familiar da criança em mais da metade dos atendimentos de menores de 6 anos de idade, com proporção significativamente maior quando a vítima era mais jovem, como foi observado entre as crianças de 0 - 1 ano (66,5\%; valor de $\mathrm{p}<0,001)$ (Tabela 4).

\section{Discussão}

Os principais resultados do VIVA Inquérito 2011 mostram que as causas externas atendidas nas urgências são, na maioria, constituídas de casos leves que evoluíram para alta, predominando os acidentes, com destaque para as quedas, seguidas de outros acidentes e acidentes de transporte. As ocorrências foram mais frequentes no domicílio, em crianças do sexo masculino e entre aquelas de 2-5 anos de idade. As agressões físicas foram o tipo mais comum de violência, sendo mais frequentes no grupo de 6-9 anos, e as negligências predominaram em crianças de 0-1 ano cujos agressores foram, majoritariamente, alguém da própria família da vítima.

Os casos aqui analisados constituem o cotidiano do atendimento realizado nos serviços de urgência e emergência, caracterizados pela menor gravidade e envolvendo menor complexidade no seu atendimento, compatíveis com outros estudos e as edições anteriores do VIVA Inquérito $3,4,7,8,9,10,11$. A estratégia de vigilância epidemiológica baseada em dados de atendimentos de urgência e emergência é adotada em diversos países e visa a identificar características das vítimas, agressores e ocorrências que não são registradas nos demais sistemas de informação, demonstrando agilidade na coleta de dados e oportunidade no fornecimento de informações úteis para propor intervenções e medidas de prevenção ${ }^{8,10}$.

Os acidentes na infância têm sido associados a variáveis como sexo, idade, etapa de desenvol-

Tabela 4

Atendimentos de emergência por violências entre crianças segundo características dos eventos por faixa etária, 24 capitais e Distrito Federal, Brasil, setembro a outubro, 2011.

\begin{tabular}{|c|c|c|c|c|c|}
\hline \multirow[t]{2}{*}{ Características } & \multicolumn{4}{|c|}{ Faixa etária (\%) [anos] * } & \multirow[t]{2}{*}{ Valor de $p$ ** } \\
\hline & $0-1$ & $2-5$ & $6-9$ & Total & \\
\hline Tipo de violência (n) & (33) & $(40)$ & (96) & (169) & $\star \star \star$ \\
\hline Física & 67,6 & 65,5 & 95,8 & 85,5 & \\
\hline Sexual & 0,0 & 4,6 & 2,3 & 2,5 & \\
\hline Negligência & 32,4 & 29,9 & 0,4 & 11,1 & \\
\hline Outros & 0,0 & 0,0 & 1,5 & 1,0 & \\
\hline Agressor familiar (n) & $(32)$ & $(40)$ & (95) & $(167)$ & 0,000 \\
\hline Sim \# & 66,5 & 55,5 & 19,9 & 33,6 & \\
\hline Não \#\# & 33,5 & 44,5 & 80,1 & 66,4 & \\
\hline Sexo do agressor (n) & $(30)$ & $(38)$ & (95) & $(163)$ & 0,041 \\
\hline Masculino & 47,1 & 64,9 & 76,4 & 70,3 & \\
\hline Feminino & 52,9 & 35,1 & 23,6 & 29,7 & \\
\hline
\end{tabular}

* Para algumas variáveis o número de atendimentos divergiu devido a dados faltantes (ignorado/em branco);

** Teste do qui-quadrado;

*** Não foram calculados o teste do qui-quadrado e o valor de p devido à existência de célula com valor < cinco;

\# Inclui pai/mãe e outro familiar;

\#\# Companheiro/ex-amigo/conhecido, agente legal público, desconhecido, outros.

Fonte: Secretaria de Vigilância em Saúde, Ministério da Saúde. Sistema de Vigilância de Violências e Acidentes -

VIVA Inquérito 2011. 
vimento neuro-psico-motor (imaturidade física e mental, inexperiência, incapacidade para prever e evitar situações de perigo, curiosidade, tendência a imitar comportamentos adultos, falta de noção corporal e de espaço, falta de coordenação motora) e características da personalidade (hiperatividade, agressividade, impulsividade e distração), além de particularidades orgânicas ou anatômicas, tais como deficiência física e/ou mental 7,11,12.

As lesões acidentais foram mais comuns nos meninos, o que é confirmado em diferentes estudos, e pode ser relacionado à maior exposição deles a situações de risco, como brincadeiras com bola, uso de bicicleta, velocípedes, patins, dentre outros 7,11,12. A ocorrência de violências também predominou no sexo masculino. Autores discutem a influência cultural e a introdução precoce dos símbolos de masculinidade, como o uso de armas, revólveres e espadas entre meninos, que trazem a simbologia do poder, banalizando precocemente os atos de violência 13 .

A faixa etária de maior ocorrência de acidentes foi a de 2-5 anos, e as violências foram mais frequentes em crianças mais velhas (6-9 anos), compatível com os achados obtidos nas edições anteriores do VIVA Inquérito 4,11,14. Porém, esse resultado nem sempre é concordante com a literatura, que demonstra maior frequência de acidentes ora em crianças mais velhas (7-12 anos) 15 , ora entre aquelas com idades de 1-3 anos 7 .

As quedas foram o tipo de acidente mais comum, o que é concordante com o descrito na literatura 7,15. Estudos também apontam que as quedas da própria altura são mais frequentes em crianças de 6-9 anos, e as de leito/mobília em crianças menores 7,11,15. Os acidentes de transporte e outros acidentes, como choque contra objetos e pessoas, ocorreram mais frequentemente em crianças mais velhas 7,11,15.

Os acidentes de transporte foram destaque nos atendimentos de emergência e constituem a primeira causa de mortalidade entre crianças de 1-9 anos de idade no Brasil e no mundo 1,2. $\mathrm{O}$ estudo apontou que as vítimas mais frequentes são os passageiros, ocupantes de veículo, e o meio de locomoção predominante na infância está relacionado às brincadeiras com bicicletas em crianças de 2-9 anos. Estudos 16,17 apontam a importância do uso da cadeirinha e de equipamentos de segurança, o transporte de crianças apenas nos bancos traseiros, além da rigorosa vigilância dos adultos ao atravessar as ruas, andar de bicicleta ou velocípedes.

As queimaduras foram mais frequentes em crianças até 5 anos, especialmente por substâncias quentes, como ocorre ao puxarem para si os recipientes com líquido quente. Deve-se reco- mendar supervisão de adultos e limitar o acesso de crianças à cozinha 18 . Acidentes envolvendo choque contra objetos/pessoa foram mais frequentes em crianças de 6-9 anos, o que pode ser explicado pela maior independência, maior exposição a brincadeiras como corridas, típicas desta faixa etária.

Verificou-se predomínio de violência física em crianças maiores e a negligência/abandono entre as mais novas, caracterizados pela omissão ou ato de deixar de prover as necessidades e cuidados básicos para o desenvolvimento físico, emocional e social da pessoa. Outros estudos têm identificado a negligencia como a principal ocorrência nessa faixa etária 19. Por outro lado, a violência sexual vem sendo identificada com maior prevalência a partir dos 10 anos e a exploração sexual a partir dos 14 anos 20. Portanto, o perfil de ocorrências pode variar conforme a faixa etária estudada, fonte de informação ou local pesquisado. Os autores da violência são, na maioria, familiares, compatível com o que tem sido apresentado em outros trabalhos que têm identificado os agressores como sendo o pai, o namorado ou companheiro da mãe e a própria mãe da vítima 21,22 .

O domicílio foi o local de ocorrência mais frequente de acidentes e violências na infância, o que pode ser consequência do maior tempo de exposição, ou seja, por ser o local onde as crianças passam a maior parte do tempo 7,12,23 Autores recomendam que os pais e responsáveis pelas crianças atentem para os riscos ambientais como tapetes soltos, pisos molhados, móveis com quinas, vidros, janelas sem proteção, berços sem proteção, camas elevadas, brinquedos espalhados, brinquedos pequenos que podem ser introduzidos como corpo estranho, objetos perfurocortantes, fogão, medicamentos e produtos de limpeza mal armazenados, animais domésticos 7,23. De toda forma, é necessário enfatizar a importância da supervisão contínua de adultos, pais ou responsáveis, que devem estar atentos aos riscos, sem impedir o desenvolvimento das crianças, estimulando as descobertas e buscando sempre protegê-las dos riscos ambientais 24 .

As lesões por acidentes e violências atingem com mais frequência a cabeça, seguida pelos membros superiores e inferiores, o que pode aumentar os riscos de lesões graves, como traumatismo craniano 25 . O desfecho mais frequente dos casos de acidentes e violências foi a alta, a internação ocorreu em maior frequência nos casos de violência/agressão, conforme descrito por outros autores 8,9 .

Dentre os limites do presente estudo, citamos a utilização da estratégia de serviços sentinelas, o que não permite estimativas popula- 
cionais, e a própria dificuldade da coleta, em especial entre as vítimas de violência, quando os eventos tendem a ser omitidos, podendo resultar em subnotificação, bem como a dificuldade na identificação e mensuração dos casos de abusos sexuais e psicológicos em crianças, especialmente quando cometidos pelos familiares. Por outro lado, a estratégia de serviços sentinelas agrega vantagens como: melhor capacitação e sensibilização da equipe para a realização do inquérito, articulação destes serviços de urgência com a rede de proteção à vítima de violência, possibilitando ações integradas e respostas às vítimas, além de possibilitar o uso das informações para o planejamento das ações de prevenção e de assistência 10,26.

O tema da violência contra a criança vem ganhando visibilidade e importância nas agendas internacionais e nacionais 1,3. No Brasil, o Estatuto da Criança e do Adolescente (Lei no 8.069/1990) estabeleceu um marco legal em defesa dos direitos da criança, que vem se consolidando a cada dia pelo trabalho local realizado pelos Conselhos
Tutelares, os Núcleos de Prevenção de Violência e Promoção da Saúde e os Centros de Referência de Assistência Social (CRAS) 6,27,28.

Os registros do VIVA Inquérito têm promovido a articulação entre saúde, serviços notificadores e de toda a rede de proteção às vitimas de violência, integrando ações de promoção à saúde, prevenção e controle de violência e injúrias (Departamento de Informática do SUS. Informações de saúde, http://www.datasus.gov.br, acessado em 15/Mar/2013) 29. Essa mobilização visa a assegurar o cumprimento de princípios legalmente estabelecidos no Estatuto da Criança e do Adolescente 27 , no que se refere às políticas e programas voltados à violência social e interpessoal contra crianças e adolescentes, direcionando as ações de promoção à saúde e prevenção destes eventos, em sua maioria, evitáveis. Da mesma forma, as injúrias na infância são eventos evitáveis e a orientação dos familiares, cuidadores e educadores pode ser uma medida simples mas que visa a evitar a maioria das ocorrências 29,30.

\section{Resumen}

El objetivo de este estudio fue analizar el perfil de las consultas de urgencia por causas externas que involucran a niños menores de 10 años en Brasil, 2011. Este estudio transversal, analizando datos de la Violencia de Vigilancia y Accidentes (VIVA), encuesta realizada en 71 servicios de urgencias y emergencias en el Sistema Único de Salud (SUS), con sede en el Distrito Federal y 24 capitales brasileñas. Como resultado de ello el 67,4 $\%$ se produjo en el entorno del hogar. Las caídas fueron las más frecuentes (52,4\%), seguidas por la colisión con objetos/personas $(21,8 \%)$ y las lesiones de tráfico
(10,9\%). Las lesiones no intencionales en la gran mayoría son evitables y se producen en el hogar y se pueden prevenir. La violencia contra los niños más pequeños son más frecuentemente cometidas por miembros de la familia y están sujetas a notificación obligatoria, destinada a la implantación de medidas de protección a las víctimas.

Niño; Heridas y Traumatismo; Violencia; Causas Externas; Servicios Médicos de Urgencia 


\section{Colaboradores}

D. C. Malta, A. C. M. Neves, M. D. M. Mascarenhas, M M. A. Silva participaram, igualmente, da concepção teórica, levantamento bibliográfico, consolidação e análise dos dados, elaboração, redação e revisão final do texto.

\section{Referências}

1. World Health Organization. World report on child injury prevention. Geneva: World Health Organization; 2008.

2. Departamento de Análise de Situação de Saúde Secretaria de Vigilância em Saúde, Ministério da Saúde. Saúde Brasil 2011: uma análise da situação de saúde e a vigilância da saúde da mulher. Brasília: Ministério da Saúde; 2012.

3. Departamento de Análise de Situação de Saúde, Secretaria de Vigilância em Saúde, Ministério da Saúde. Viva: vigilância de violências e acidentes, 2008 e 2009. Brasília: Ministério da Saúde; 2010. (Série G. Estatísticas e Informação em Saúde).

4. Mascarenhas MDM, Malta DC, Silva MMA, Lima CM, Carvalho MCO, Oliveira VLA. Violência contra a criança: revelando o perfil dos atendimentos em serviços de emergência, Brasil, 2006 e 2007. Cad Saúde Pública 2010; 26:347-57.

5. Oliveira BRG, Thomazine AM, Bittar DB, Santos FL, Silva LMP, Santos RL, et al. A violência intrafamiliar contra a criança e o adolescente: o que nos mostra a literatura nacional. REME Rev Min Enferm 2008; 12:547-56.

6. Assis SG, Avanci JQ, Pesce RP, Pires TO, Gomes DL. Notificações de violência doméstica, sexual e outras violências contra crianças no Brasil. Ciênc Saúde Coletiva 2012; 17:2305-17.
7. Martins CBG. Acidentes na infância e adolescência: uma revisão bibliográfica. Rev Bras Enferm 2006; 59:344-8.

8. World Health Organization. Injury surveillance guidelines. Geneva: World Health Organization; 2001.

9. World Health Organization. Injuries and violence the facts. Geneva: World Health Organization; 2010.

10. World Health Organization. Guidelines for conducting community surveys on injuries and violence. Geneva: World Health Organization; 2004.

11. Malta DC, Mascarenhas MDM, Bernal RTI, Viegas APB, Sá NNB, Silva Júnior JB. Acidentes e violência na infância: evidências do inquérito sobre atendimentos de emergência por causas externas - Brasil, 2009. Ciênc Saúde Coletiva 2012; 17:2247-58.

12. Fonseca SS, Victora CG, Halpern R, Barros AJD, Lima RC, Monteiro LA, et al. Fatores de risco para injúrias acidentais em pré-escolares. J Pediatr (Rio J.) 2002; 78:97-104

13. Souza ER. Masculinidade e violência no Brasil: contribuições para a reflexão no campo da saúde. Ciênc Saúde Coletiva 2005; 10:59-70.

14. Malta DC, Mascarenhas MDM, Silva MMA, Macário EM. Perfil dos atendimentos de emergência por acidentes envolvendo crianças menores de dez anos: Brasil, 2006 a 2007. Ciênc Saúde Coletiva 2009; 14:1669-79. 
15. Filócomo FRF, Harada MJS, Silva CV, Pedreira MLG. Estudo dos acidentes na infância em um pronto-socorro pediátrico. Rev Latinoam Enferm 2002; 10:41-7.

16. Oliveira SRL, Leone C, Carvalho MDB, Santana RG, Lüders LE, Oliveira FC. Erros de utilização de assentos de segurança infantil por menores de 4 anos. J Pediatr (Rio J.) 2012; 88:297-302.

17. Garcia LP, Freitas LRS, Duarte EC. Avaliação preliminar do impacto da Lei da Cadeirinha sobre os óbitos por acidentes de automóveis em menores de dez anos de idade, no Brasil: estudo de séries temporais no período de 2005 a 2011. Epidemiol Serv Saúde 2012; 21:367-74.

18. Martins CBG, Andrade SM. Queimaduras em crianças e adolescentes: análise da morbidade hospitalar e mortalidade. Acta Paul Enferm 2007; 20:464-9.

19. Faleiros JM, Matias ASA, Bazon MR. Violência contra crianças na cidade de Ribeirão Preto, São Paulo, Brasil: a prevalência dos maus-tratos calculada com base em informações do setor educacional. Cad Saúde Pública 2009; 25:337-48.

20. Costa COM, Carvalho RC, Bárbara JFRS, Santos CAST, Gomes WA, Sousa HL. O perfil da violência contra crianças e adolescentes, segundo registros de Conselhos Tutelares: vítimas, agressores e manifestações de violência. Ciênc Saúde Coletiva 2007; 12:1129-41.

21. Rimsza ME, Schackner RA, Bowen KA, Marshall W. Can child deaths be prevented? The Arizona child fatality review program experience. Pediatrics 2002; 110(1 Pt 1):e11.

22. Hamilton LHA, Jaffe PG, Campbell M. Assessing children's risk for homicide in the context of domestic violence. J Fam Violence 2013; 28:179-89.
23. Paes CEN, Gaspar VLV. As injúrias não intencionais no ambiente domiciliar: a casa segura. J Pediatr (Rio J.) 2005; 81 Suppl:s146-54.

24. Dedoukou X, Spyridopoulos T, Kedikoglou S, Alexe DM, Dessypris N, Petridou E. Incidence and risk factors of fall injuries among infants. Arch Pediatr Adolesc Med 2004; 158:1002-6.

25. Koizumi MS, Mello Jorge MHP, Nóbrega LRB, Waters C. Crianças internadas por traumatismo crânio-encefálico no Brasil, 1998: causas e prevenção. Inf Epidemiol SUS 2001; 10:93-101.

26. Gawryszewski VP, Silva MMA, Malta DC, Mascarenhas MDM, Costa VC, Matos SG, et al. A proposta da rede de serviços sentinela como estratégia de vigilância de violências e acidentes. Ciênc Saúde Coletiva 2006; 11:1269-78.

27. Brasil. Lei no 8.069 de 13 de julho de 1990. Dispõe sobre o Estatuto da Criança e do Adolescente, e dá outras providências. Diário Oficial da União 1990; 16 jul.

28. Malta DC, Silva MMA, Mascarenhas MDM, Souza MFM, Morais Neto OL, Costa VC, et al. A vigilância de violências e acidentes no Sistema Único de Saúde: uma política em construção. Divulg Saúde Debate 2007; 39:82-92.

29. Gaspar VLV, Lamounier JA, Cunha FM, Gaspar JC. Fatores relacionados a hospitalizações por injúrias em crianças e adolescentes. J Pediatr (Rio J.) 2004; 80:447-52.

30. Emery CR, Nguyen HT, Kim J. Understanding child maltreatment in Hanoi: intimate partner violence, low self-control, and social and child care support. J Interpers Violence 2014; 29:1228-58.

Recebido em 03/Mai/2014

Versão final reapresentada em 29/Nov/2014

Aprovado em 08/Dez/2014 